\title{
A Qualitative Analysis on the Obstacles of Sustainability Transformation in Dhaka City
}

\author{
Rabiul Karim \\ Department of Economics, Asian University of Bangladesh, Dhaka, Bangladesh \\ Email: mridul5121@gmail.com
}

\begin{abstract}
Dhaka is one of the fastest growing mega-cities in the world. Nearly $36 \%$ of the urban population lives in the capital of Bangladesh. Nearly 17.4 million people are living in this city at present. The population is increasing approximately at $1.65 \%$ per year in Dhaka city. As a fastest growing mega-city in the world, Dhaka is attracting an estimated 300,000 to 400,000 mostly poor migrants a year. That's creating pressure on the ongoing poverty level in the city. Poverty affects a third of Dhaka's residents, mostly living in slums. The densely populated capital of Bangladesh continues to dominate the list of world cities with the worst air quality. Dhaka occupied the first position in the list. Besides natural causes, unplanned infrastructural development, inadequate and inefficient drainage are the main causes of floods and water logging in Dhaka city. Due to lack of planned growth in the city, chaotic urbanization has come up with many serious problems including large and fast growing slum areas lacking basic services (especially lack of access to proper sanitation, safe drinking water and clean and affordable energy) and municipal solid waste (MSW) are being generated at a faster pace, posing a serious management and environmental threats in the Dhaka city. Planned urbanization is quickly becoming a necessity though this may cause numerous challenges for the government. Bangladesh has some strategic plans to accomplish sustainable development with other countries by 2030 . This paper is going to analyze the major challenges in the way of sustainability transformation of Dhaka city and their way out.
\end{abstract}

Keywords: Sustainability Transformation; Access to Clean Water and Sanitation; Clean and Affordable Energy; Climate and Environment; SDG Achievement.

\subsection{INTRODUCTION}

Dhaka is one of the fastest growing mega-city in the world. Nearly $36 \%$ of the urban population lives in the capital of Bangladesh. For a better livelihood, to avail opportunities of earning more and more people are moving to Dhaka every year. This migration contributes around $63 \%$ to the increase in population which leaves Dhaka currently with about 17.4 million people. Moreover, the population is increasing approximately at $1.65 \%$ per year. Planned urbanization and development is quickly becoming a necessity though this may cause numerous challenges in the city life. But with the proper initiatives and good governance, if sustainable development goals are being achieved in Dhaka city, the city can turn into one of the most developed cities in the world. But there are too many challenges and obstacles to transform this city to a sustainable city including the problems of housing, education, healthcare facilities, social security, sanitation and so many. With a lot of shortage in needs, limited resources and living space, the city is becoming more crowded.
Although there are some of the mega development projects are visible in the city, but that do not reduce the challenges.

Due to lack of planned growth in the city, chaotic urbanization has come up with many serious problems including large and fast growing slum areas lacking basic services (especially lack of access to proper sanitation, safe drinking water and clean and affordable energy) and municipal solid waste (MSW) are being generated at a faster pace, posing a serious management and environmental threats in the Dhaka city. Domestic waste management is a challenging task as the size of the population is increasing and producing more waste, besides the type of waste is changing. Waste generation is affected by different socio economic elements, demographic nature of the city, periodic factors, lack of awareness and weak management practice. Waste management process and practice needs to be reconstructed.

Dhaka as well as the other urban cities like Dhaka are the center for culture, education, science, impression, business and commerce, production, industry and national and international trade. People living in the city are more advance 
economically then the other part of the country. But challenges are not too small. Many challenges exist in the city including common urban challenges like congestion, over population, lack of funds to provide basic services, a shortage of adequate housing, healthy environment, good infrastructure, corruption etc. To build a sustainable city these challenges are need to overcome as early as possible.

United Nation set up the Sustainable Development Goal 11: create cities comprehensive, safe, resilient and sustainable, this is projected to rise to $60 \%$ by 2030 , with almost all the urban growth occurring in low- and middleincome countries. Regardless of size, cities will become the new home of the biggest share of many uncountable migrants. Nearly 828 million people live in slums these days and therefore the range keeps escalating. The world's cities occupy just three per cent of the Earth's land, but account for $60-80 \%$ of energy consumption and seventy-five per cent of carbon emissions. Rapid urbanization is exercising pressure on existing water supply, sewage, electricity, living environment and public health. That's why it is very essential to reduce this pressure in the city heart to bring it to a sustainable city.

Like other developing countries of the world, urbanization in Bangladesh is a growing aspect, which is stable in nature however anxiously affects urban property and reducing the scope smooth governance. Despite urban authorities are involved concerning this issue, but they often fail to address the actual issues that are responsible for the uncontrollable and unpredictable rural to urban migration and negligence of urban poor's sustainable living and access to basic services. Virtually the rural destitution shortcoming shave been converse to urban areas, particularly in Dhaka city, Bangladesh. Inadequacy of infrastructural services, basic amenities and environmental goods; environmental degradation; traffic jam and accidents; violence and socioeconomic insecurity area unit the key challenges that are created through hurried urbanization. The aims of the study were to find out the major challenges that are responsible to transform the Dhaka city to a long lasting and sustainable city.

However, the primary data for this study was collected through a checklist interview survey and the relevant secondary was collected from published and unpublished sources. The published article or reports were collected by searching internet and unpublished article or reports were collected from project document and university library papers.

\subsection{OBJECTIVE OF THE STUDY}

The main objectives of the study are to find out the obstacles and challenges of the sustainability transformation of Dhaka city in Bangladesh.

Other major objectives are:

- To identify the factors responsible to the way of sustainable transformation of Dhaka city.

- To acquire knowledge and idea regarding challenges to the long term sustained development of Dhaka city including environmental issues, social security, over population etc.

- To identify possible methods and measures to improve the development status of Dhaka city to a sustainable level.

- To outline some recommendation for the transformation of Dhaka city to a sustainably developed city.

\subsection{METHODOLOGY OF THE STUDY}

- The study has been based on both primary and secondary sources of data and information.

- The primary data has been collected through a check list interview and prescribed questionnaires from the population of Dhaka city of different occupations and different locations. Sampling method is being followed.

- The sample size of the study was selected on the basis of random sampling technique. That was collected from 400 numbers of peoples living in Dhaka city.

- The secondary sources of data and information are from published books and journals periodicals, newspaper, and records of different offices.

- The research is an empirical study and explanatory. Qualitative research method has been followed.

- To prepare the sample survey questioner SDG goal indicators has been followed.

- To analyze the data collected from the respondents, the cross-tabulation data analysis has been followed. 


\subsection{LIMITATIONS OF THE STUDY}

Sample size: The sample size of this study was too small in terms of the total populations of Dhaka city.

Lack of available and reliable data: We had limited scope to avail the necessary data and information for this study because of some practical reasons.

Lack of prior research studies on the topic: We faced problems to find the prior research articles in the related topics. There is some research may be done before, but it was hard to reach them within this pandemic period.

Measure used to collect the data: The measures we have followed to evaluate the study, there may be some gap. Because of this gap data and information may not be measured properly.

Time -Data collection time was too short to reach more people. Besides because of Covid-19 pandemic, it was too hard to meet the people of different locations.

\subsection{REVIEW OF LITERATURE}

Chauhan, 2016, in his article engraves about the 'shift of Millennium Development Goals to Sustainable Development Goals'. The article sights 17 Goals and its minute cultivation of the themes undertaken. The article portrays the goals and its relevance to the other aspects. The article analytically explains the Sustainable Development Goals in a minute level.

Chakrabarti, 2015, In 'Climate Change and Sustainable Development' debates the multifaceted issue of global concern, dealing with climate change has emerged as the key challenge of the present, for the sustainable development of the future. Swelling emission of greenhouse gases (GHGs), intensifying temperature, and the resulting changes in rainfall pattern, melting glaciers, rising sea level, and extreme climatic events are having profound impacts on almost every aspect of life on earth including air, water, food, human living and, health. The risks of disasters - requiring a multi-dimensional approach for alleviating and adapting at all levels and in all sectors.

Sachs, in The Age of Sustainable Development, 2015, draws attention on so many discrete grounds of inquiry on the profound research and wisdom of the global sustainable development community. The author illustrates, sustainable development is both a way of looking at the world, with a focus on the inter linkages of economic, social, and environmental change, and a way of relating our shared aspirations for a decent life, uniting economic development, social inclusion, and environmen 1 sustainability.

Prajapati, 2017, in his article named 'Sustainable Development Goals and Economic Stability in Indian Economy' has specified the internal stability of the nation by endowing youth for the development, wherein the youth are guided and directed to take their own decisions for the life. The researcher further underlines the sustainable development goals and poverty alleviation and behavioral change for the protection of climate and environment and bringing social development.

Jha \& Poddar, 2010, In a research study titled 'Sustainable Development: An Empirical Analysis', explains the theoretical framework relating to the sustainable development for congenial social environment and intergenerational equity essential to sustain the fruits of development.

\subsection{UNDERSTANDING SUSTAINABLE DEVELOPMENT}

The concept "sustainable development" has a long history and it involves a much deeper meaning than it appears. "Sustainable development" was used for the first time in the Brundt land Commission report "Our Common Future" in 1987. In the report, the commission devised what has become the most often-quoted definition of sustainable development: "development that meets the needs of the present without compromising the ability of future generations to meet their own needs. The sustainable development means to reach and find out a certain point of development that ensures the environmental balance and keep climate to its logical level. Maintaining the development over time is also sustainable development. It is true that, the economies of the world are developing over time. The effects and outcomes of this development are high on the environment as well as on the climate. The ecosystem we live in is not so much strong to face these effects. To reach the sustainable development 
the ecosystem needs to keep safe and sound from any kind of threats. Actually the word sustainability means a function of social, economic, technological and ecological melodies. It engenders a more reflective definition of sustainable development as: "the need to ensure a better quality of life for all, now and into the future, in a just and equitable manner, whilst living within the limits of supporting ecosystems." The notion of sustainable development must be understood in terms of human needs, security and right sand responsibility towards the environment as well as in terms of solidarity between generations and between communities.

Sustainable development implies the fulfillment of numerous conditions: conserving the overall balance, protection for the environment, and averting the fatigue of natural resources. Reduced production of waste, ensuring efficient level of production and energy consumption must also be implemented. Sustainable development is presented as a more or less clean break from other modes of development, which have led and are still leading to worrying social and ecological damage on both a worldwide and a local scale.

The exercise of sustainability is about generating new ways to live and prosper while ensuring an equitable, sound and healthy future for all the people and for the planet. So, sustainability is something where the environment and development of the society all together have to reach the point of reconciliation. And sustainable development is the development that meets the needs of the present without compromising the ability of coming generations to meet their own needs.

\subsection{SUSTAINABLE DEVELOPMENT AND BANGLADESH}

Bangladesh has some strategic plans to accomplish sustainable development with other countries by 2030. The People's Republic of Bangladesh proclaims "The state shall endeavor to protect and improve the environment and to preserve and safeguard the natural resources, biodiversity, wetlands, forest and wildlife for the present and future citizens." Sustainable development is thus a constitutional obligation in Bangladesh. It is also based on the globally accepted principles of sustainable development defined through- Rio Declaration and Agenda 21, Johannesburg Declaration and Implementation Plan and Environment and Development in Asia and the Pacific. The NSDS has addressed mainstreaming sustainable development challenges across sectors and integrate economic, social and environmental objectives across sectors. It also embraces mechanism for monitoring implementation progress and institutional mechanism for people's participation. In the sustainable development plan of Bangladesh, sustainability transformation of Dhaka city is included with priority as Dhaka is the capital and principle city of the country. If Bangladesh wants to achieve sustainable development goals, then sustainable transformation of Dhaka city is needed for must. But the way of attaining the goals is not so easy. Bangladesh needs to overcome some of the specific obstacles in the way of achieving sustainable development. In this paper we are trying to find out the some of the basic challenges and obstacles that are in front of Bangladesh to transform the Dhaka city to a sustained city.

\subsection{SUSTAINABLE DEVELOPMENT: DHAKA CITY CONTEXT}

Dhaka is one of the fastest growing mega-cities in the world. Nearly $36 \%$ of the urban population lives in the capital of Bangladesh. For a better livelihood, in search of more opportunity more and more people are migrating to urban cities like Dhaka. This migration contributes around 63\% to the increase in population which leaves Dhaka currently with about 17.4 million people. Moreover, the population is increasing approximately at $1.65 \%$ per year. Planned urbanization is quickly becoming a necessity though this may cause numerous challenges for the government. But with the proper and efficient management and right governance, sustainability transformation of Dhaka can turn the city into one of the most developed city in the world. But there are some challenges and strong obstacles that's are need to overcome first with priority.

Dhaka is under a huge threat from environmental imbalance and climate change. A slight increase in global water levels can submerge a significant portion of the city that is very alarming. Moreover, lack of proper urban planning and unhealthy living style of the city people, the 
city is becoming more polluted every day. Air and water pollution is a common phenomenon in the city. Recently, Dhaka has been declared as the city with the most polluted air. Besides this, there are constant problems with water supply, solid waste management, the sewer and drainage system, public transportation, health care services and governance. Corruption is a common culture in the city for long time. The living standard of the common people in the city is relatively low with consideration of global standard. Above all unplanned urbanization has led to the cost of living in Dhaka to be increasing at an overwhelming rate. Dhaka must overcome these challenges if it is to sustain as a developing city in the long run.

\subsection{FIELD STUDY ANALYSIS}

For the field study of this analysis the primary data has been collected through a checklist interview using internet based questioner survey among the peoples of different occupations living in Dhaka city. The survey questioner includes total 20 specific questions related to sustainable development according to SDG goals set by United Nations. The questioner includes poverty situations of the people, environmental issues, wastage management, water and sanitation, social security and safety, living standard of the people living in the Dhaka city and so on. In this sample survey a total of 400 respondent participated and they expressed their views about the variables we selected for the study.

\subsection{EARNINGS OF THE PEOPLE IN DHAKA CITY}

To have idea about the living standard of the peoples in Dhaka city, there was a question to the respondent about their monthly income. Based on the respondent's opinion the results we found that almost 18.67 percent people have the income just below 10,000 Taka per month. 22.2 percent of the peoples have the income from 20,000 to 30,000 Taka. 16.7 percent peoples have the income of above 40,000 Taka per month.

Table 1: Earnings of the People Living in Dhaka

\begin{tabular}{|ll|}
\hline Earnings per month (Taka) & Percentage \\
Below 10,000 Taka & $18.67 \%$ \\
10,000-20,000 Taka & $11.2 \%$ \\
$20,000-30,000$ Taka & $22.2 \%$ \\
\hline
\end{tabular}

30,000- 40,000 Taka $\quad 16.7 \%$

Above 40,000 taka

$16.7 \%$

\subsection{RESIDENTS}

The study found that in Dhaka city, most of the peoples living in a rented home. Among the city duelers in Dhaka, 81.6 percent of them are living in a home on rental basis. Only 19.4 percent peoples have their personal residents.

Graph-1: Residents type of Dhaka city People.

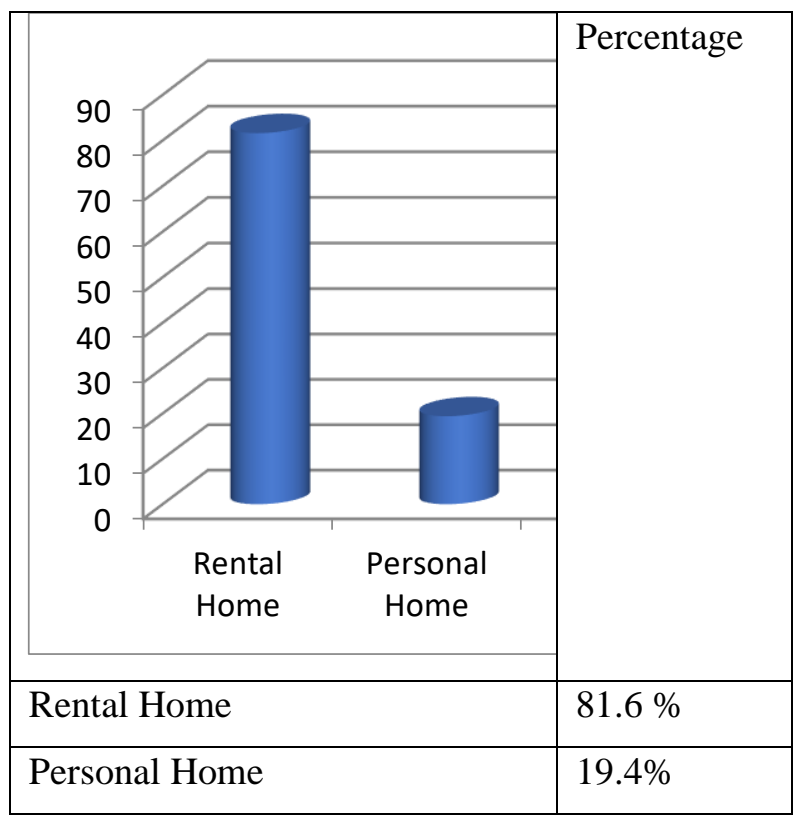

\subsection{WATER SUPPLY AND WATER MANAGEMENT}

The peoples living in Dhaka city are facing various problems regarding proper water supply and water management. The study found that peoples are very dissatisfied about the water supply. There are 36.8 percent of the peoples are strongly dissatisfied with the pure water supply. Slightly satisfied peoples are 31.6 percent. Only 5.3 percent of the peoples are fully satisfied with the current water supply and drinking water management.

Table 2: Water Supply Satisfaction in Dhaka City

\begin{tabular}{|ll|}
\hline Satisfaction level & Percentage \\
Fully Satisfied & $5.3 \%$ \\
satisfied & $26.3 \%$ \\
Slightly satisfied & $31.6 \%$ \\
Strongly dissatisfied & $36.8 \%$ \\
\hline
\end{tabular}




\subsection{WASTE AND WASTAGE MANAGEMENT}

To ensure the sustainable development of a city this is very essential to establish a proper wastage management system. But the scenario in Dhaka city is very disappointing. The study found that no one in the city is happy with the wastage management. Fully satisfied peoples percentage is a total zero. 52. 6 percent of the peoples are dissatisfied with the current wastage management status. Only 10.5 percent are satisfied.

Graph-2: Wastage management satisfaction level in Dhaka city.

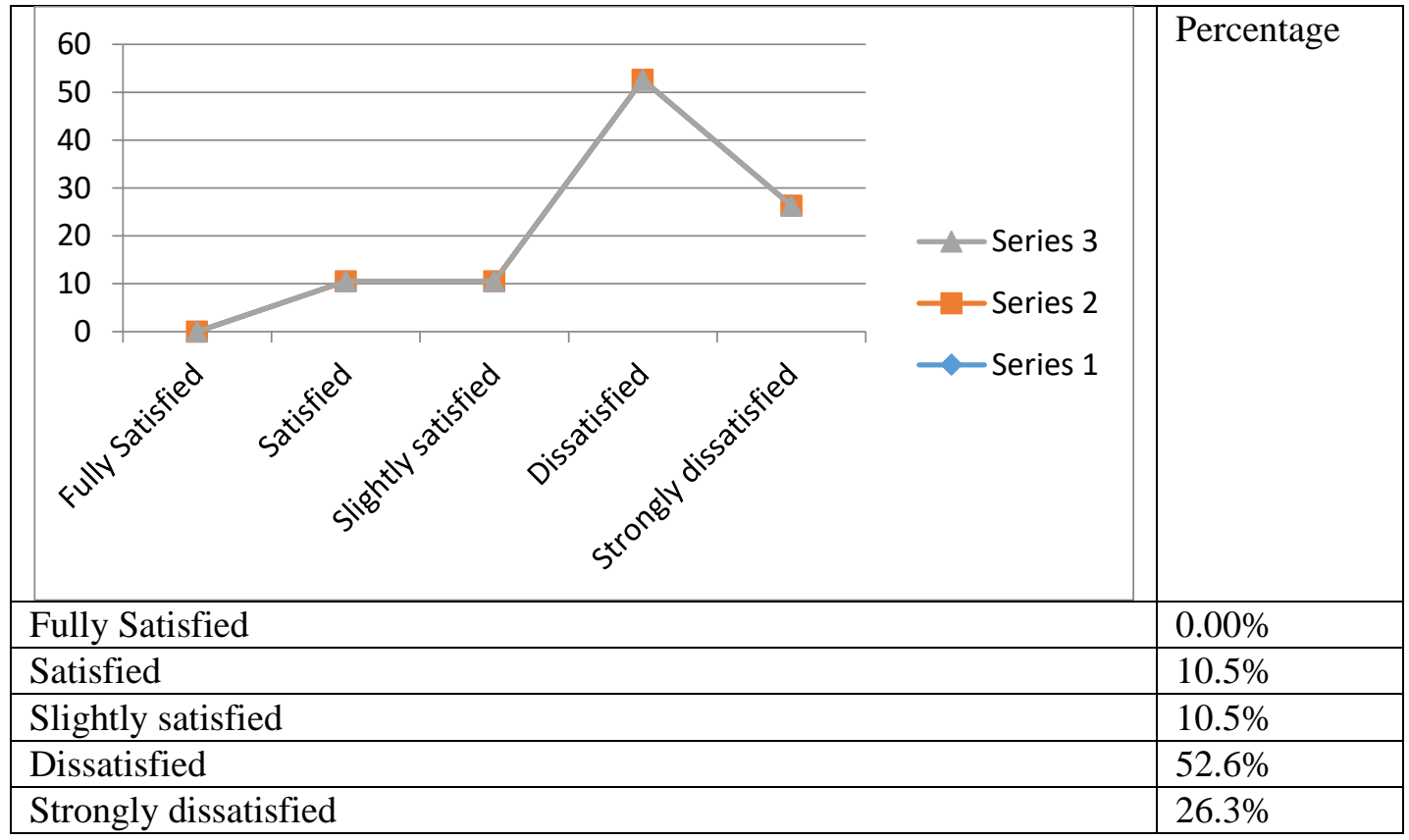

\subsection{SECURITY AND SOCIAL SAFETY IN DHAKA CITY}

Security and social safety status of the peoples living in Dhaka city also found a result that is alarming for the sustainable transformation of a city. Because social security and safety of the people is must for the sustainable development. But the study found that, in Dhaka city, $47.4 \%$ of the people do not feel secured. That's a huge number.

Table 3: Social Safety in Dhaka City

\begin{tabular}{|ll|}
\hline Safety and Security Satisfaction & Percentage \\
Yes & $36.8 \%$ \\
No & $47.4 \%$ \\
Strongly No & $15.8 \%$ \\
\hline
\end{tabular}

2.7. ENVIRONMENT AND CLIMATE CHANGE IN DHAKA CITY
From the environmental perspective Dhaka city is suffering due to excessive amounts of pollution including air, water and sound. Dhaka is almost a city of pollution and this in a threat of dangerous climate change. Peoples living in this city, most of them are think that the weather of Dhaka is not safe for a healthy life. Among the peoples of Dhaka, $31.6 \%$ strongly opposed the living standard of Dhaka. $42.1 \%$ think that the weather of Dhaka is not safe for living a good life.

Table 4: People's Perception about Dhaka City Weather

\begin{tabular}{|ll|}
\hline $\begin{array}{l}\text { Weather healthiness of Dhaka } \\
\text { city }\end{array}$ & Percentage \\
Strongly No & $31.6 \%$ \\
No & $42.1 \%$ \\
Yes & $21.1 \%$ \\
Strongly Yes & 0 \\
No comments & $5.3 \%$ \\
\hline
\end{tabular}




\subsection{LIVING FACILITIES IN DHAKA CITY}

The study found that most of the peoples in Dhaka city live in rental home. Nearly 81.6 percent of the city people live in the home on rental basis as we mentioned in a table above. The points here we want to disclose that, 63.2 percent of the city dwellers face problems sometimes to pay the house rent. 10.5 percent faces problem on very frequent basis. 26.3 percent of Dhaka people do not face any problem to pay the rent regularly.

Graph-3: House rental problem in Dhaka city.

\begin{tabular}{|l|l|l|}
\hline \multicolumn{2}{|c|}{ HOUSE RENT PROBLEM IN DHAKA } & Percentage \\
& CITY & \\
& & \\
\hline Frequently SOMETIMES CATEGORY 3 & \\
\hline Sometimes & $10.5 \%$ \\
\hline Not at all & $63.2 \%$ \\
\hline
\end{tabular}

\subsection{INCOME AND DAILY LIFE MAINTENANCE}

Dhaka is a city of excessive expense. General Price trend in the city is always high. That's why the lower and middle income group in this city always suffers from various problems. The study found that $42.1 \%$ of the people spend all of their monthly income to pass the month. $15.8 \%$ people spends their $90 \%$ of income every month. 26.3 percent people spend more than $50 \%$ of their income per month.

\section{Table 5: Per Month Expense in Dhaka City}

\section{Monthly Expense in Dhaka City Percentage}

$100 \%$ of the income per month $\quad 42.1 \%$
$90 \%$ of the income per month $\quad 15.8 \%$

$80 \%$ of the income per month $\quad 5.3 \%$

$50 \%$ of the income per month $\quad 26.3 \%$

\subsection{DRAINAGE AND SEWERAGE MANAGEMENT IN DHAKA CITY}

To establish a sustainable city this is very essential to have a proper drainage and sewerage system in the city. But the case is very alarming in the context of Dhaka city as the city face water halt on regular basis if there is a slight rainfall. $68.4 \%$ of the Dhaka city peoples are not happy with the drainage system. Percentage of happy people is only $5.3 \%$.

Graph-4: Public opinion about the Drainage system.

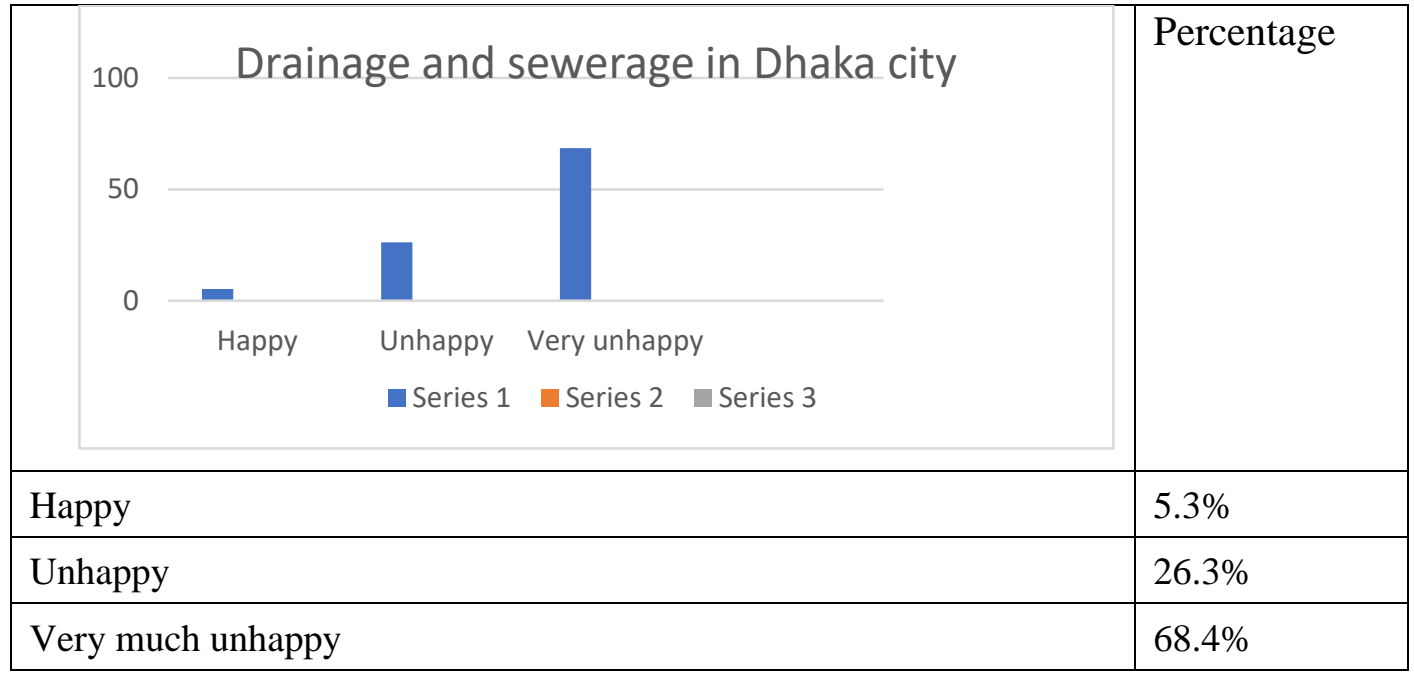




\subsection{HEALTH SERVICE IN DHAKA CITY}

For the Sustainable development of a city a proper health service and health system is very essential. The study found that 57.9 percent of the Dhaka city people are not happy with the health service the received. 31.6 percent and very unhappy. The percentage of happy people is only 5.3 percent.
Table 6: Health Service in Dhaka City

\begin{tabular}{|ll|}
\hline Health Service & Percentage \\
Happy & $5.3 \%$ \\
unhappy & $57.9 \%$ \\
Very unhappy & $31.6 \%$ \\
\hline
\end{tabular}

\subsection{EDUCATION IN DHAKA CITY}

Among the people living in Dhaka city, 57.9 percent of the people think that the education cost in the city is very high. 42.1 percent think it is high in terms of their income.

Graph-5: Cost of Education in Dhaka city

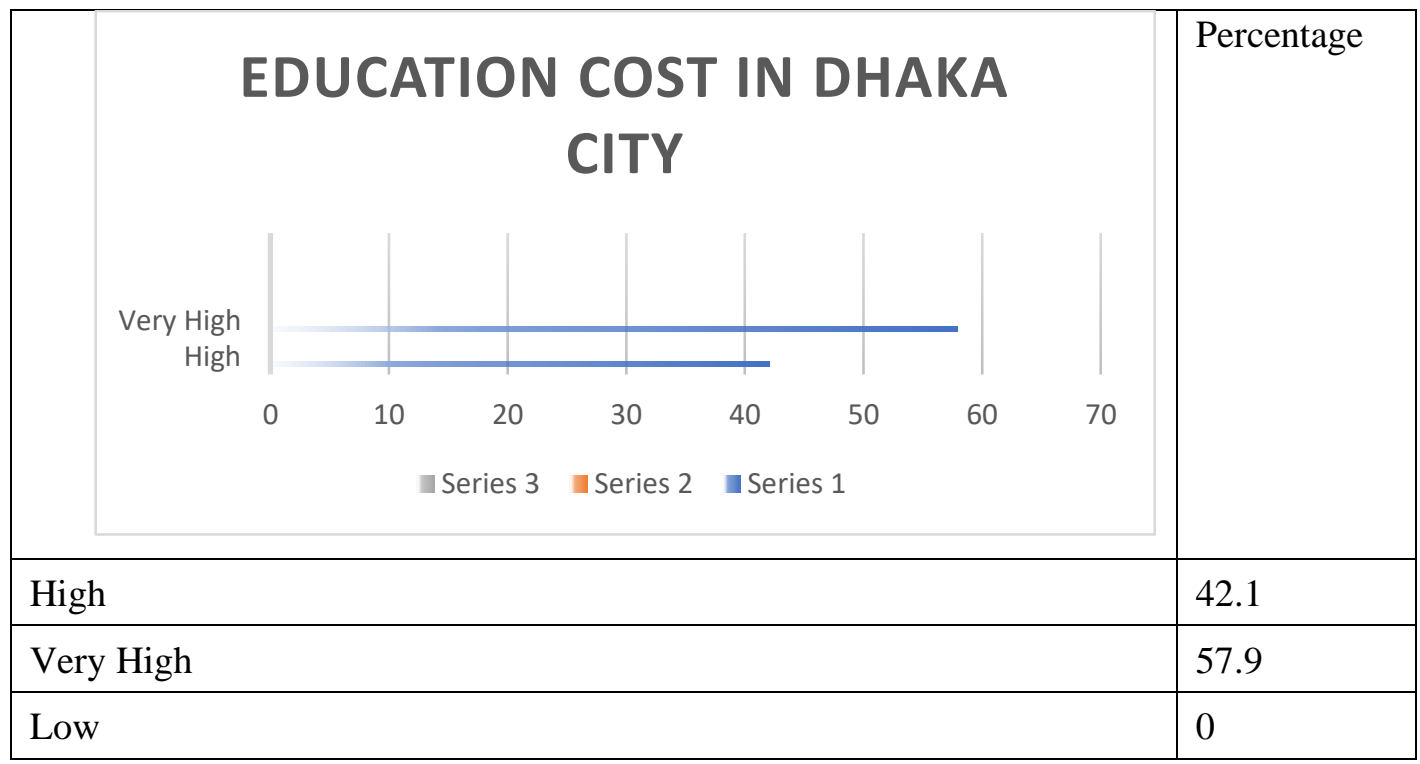

\subsection{INCOME DISTRIBUTION IN DHAKA CITY}

The study found that the income distribution status in Dhaka city is not in a good position in terms of the sustainable development goal's level. Among the city people in Dhaka $21.1 \%$ of the people think that the income distribution level is very imbalanced in Dhaka city. 47.4 percent of the people think that the discrimination in income distribution of Dhaka is increasing day by day.

\section{Table 7: Income Discrimination in Dhaka City}

\begin{tabular}{|ll|}
\hline $\begin{array}{l}\text { Discrimination in Income } \\
\begin{array}{l}\text { Very imbalanced income } \\
\text { distribution }\end{array}\end{array}$ & Percentage \\
$\begin{array}{l}\text { Balanced income distribution } \\
\begin{array}{l}\text { Discrimination is increasing day } \\
\text { by day }\end{array}\end{array}$ & $21.1 \%$ \\
\hline
\end{tabular}

\subsection{Main Problem to Gain SDG Goals}

89.5 percent of the people living in Dhaka city think that corruption is the main problem in the way of sustainable development of this city. 10.5 percent of the people think that mismanagement is the reason here. No one think that there is a shortage of budget.

Table 8: Problems to the Way of SDG Goals

\begin{tabular}{|ll|}
\hline Problems in the way of SDG goal & Percentage \\
Corruptions & 89.5 \\
Mismanagement & 10.5 \\
Lack of budget & 5.3 \\
\hline
\end{tabular}




\subsection{CHALLENGES AND OBSTACLES TO SUSTAINABLE TRANSFORMATION OF DHAKA CITY}

Dhaka is the most populated city in Bangladesh, and it is also one of the most populated cities in the world. The Greater Dhaka Area has a population of over 18 million as of 2016, while the city itself has a population estimated at 8.5 million. This city faces lots of challenges to the way of sustainable development. The challenges of sustainable transformation of Dhaka city in Bangladesh are described based on respective sectors.

\subsection{POVERTY AND SOCIAL INSECURITY}

The poverty situation in the biggest cities of the Third World countries suggests that these bigger size cities are very small for the poor's. They create huge opportunities for the riches, but shows worse reality to the poor. It is generally assumed that urban poverty levels are lower than rural poverty levels, but the absolute number of poor and malnourished is rapidly increasing in the cities. Dhaka is no exception. As a fastest growing megacity in the world, Dhaka is attracting an estimated 300,000 to 400,000 mostly poor migrants a year. That's creating pressure on the ongoing poverty level. Poverty affects a third of Dhaka's residents, mostly living in slums. Adequate access to shelter, basic services, and a living wage are major challenges for the poor. Crime and violence have also become a major problem in Dhaka, particularly affecting the poor. The institutional deficiencies in Dhaka impede effective city management and poverty concerns. The urban poor spend a substantial portion of their income on treating illness and are more vulnerable to lose wages and have less job security when they are forced to miss work - all of which erodes their coping capacity and can keep potentially mobile families trapped within a cycle of poverty. These challenges need to overcome.

\subsection{URBAN ENVIRONMENT}

According to the World Health Organization (WHO), air pollution kills an estimated seven million people worldwide every year. The densely populated capital of Bangladesh continues to dominate the list of world cities with the worst air quality. Dhaka occupied the first position in the list. The city of Beijing in China occupied the second place. The third and fourth spots were grabbed by Kathmandu of Nepal and Delhi of India, respectively. Dhaka's air quality index (AQI) was recorded at 237 around $2 \mathrm{am}$, which is considered 'very unhealthy" (February 26, 2021, Daily Dhaka Tribune). An AQI between 201 and 300 is considered "poor," while a reading of 301 to 400 is said to be "hazardous," posing serious health risks to city residents.

AQI, an index for reporting daily air quality, is used by government agencies to inform people how clean or polluted the air of a certain city is, and what associated health effects might be a concern for them. In Bangladesh, the overall AQI is based on five criteria pollutants - Particulate Matter (PM10 and PM2.5), NO2, CO, SO2, and Ozone (O3). Bangladesh has a subtropical monsoon climate characterized by wide seasonal variations in rainfall, high temperatures and humidity. Generally, Dhaka's air starts getting fresh when monsoon rains begin in mid-June. The air remains mostly acceptable from June to October. In February last year, Bangladesh's Environment, Forests and Climate Change Minister Md Shahab Uddin admitted that air pollution levels in the capital "has reached an extreme level."

\subsection{CHALLENGES IN ENERGY SECTOR}

Bangladesh has to face lots of tribulations in power and primary energy sector. There are huge challenges to increase the use of renewable energy sources in a proper manner. The country has a very limited energy reserve; small amounts of oil, coal and countable natural gas reserves. The country suffers an internal energy struggle, as about $93 \%$ of the country's power producing thermal plants is gas-based, but the gas is also needed for the industrial sector. Therefore, the country has to continuously- make some compromises between power production and developing the industrial sector. The power sector in Bangladesh is highly dependent on fossil fuels, as natural gas and coal are the dominating sources for power generation in the country. About $62.9 \%$ of Bangladeshi generated electricity comes from natural gas, while $10 \%$ is from diesel, $5 \%$ comes from coal, $3 \%$ of heavy oil, and $3.3 \%$ is of renewable sources. 
Despite the fact that the Bangladeshi energy sector uses and covers varied products; electricity, petroleum products, natural gas, coal, biomass and solar, yet the policy and decision makers are mostly pre-occupied with electricity, as it is the most common used form of energy in the country. Thus, because there is a continuous and rapidly widening gap between electricity supply and demand, therefore it is a major challenge for the energy sector in Bangladesh. Power cuts and the low reliability of the power supply are the major problem of the grid extension. There has been a massive expansion of the grid infrastructure and other electrification measurements, the electrification rate is around $75 \%$, but in reality many households suffer from unreliable electricity supply with power outages of up to 14 hours per day. However, the number of connections is in fact increasing rapidly with around 250.000 per month. The supply of population and industry with modern energy is very low compared to countries with similar economies. The per-capita production of commercial energy increased since 2010 to $371 \mathrm{kWh}$, but is still one of the lowest in the world. Bangladesh will probably need to triple that amount in order to achieve its target to become a middle income country by 2021 .

\subsection{NATURAL AND MAN- INDUCED HAZARDS}

Flood and water logging are the most regular hazard in the cities of Bangladesh, especially in Dhaka and Chittagong. Besides natural causes, unplanned infrastructural development, inadequate and inefficient drainage are the main causes of floods and water logging in Dhaka city. Diminishing water bodies and interrupted river flows are also encouraging factors of weakening the situations. Once there were number of canals in Dhaka city, which are now mostly crammed up for settlements and business purposes. The Dhaka City Protection Embankment that was built spending huge resources is not properly maintained by the authority. A lot of urban poor have built their houses and shops on the embankment, land grabbers have taken over a large part, which gradually damaging its strengths and capacity. In 2004, almost 2.5 million people were affected by flood, and 20 people had died (Islam and Hasan 2004). CUS (2006) reports that more than $60 \%$ slums in the city were affected by floods, in which $38.5 \%$ were fully affected. Alam and Rabbani
(2007) also states sufferings and extent of 1998 flood in Dhaka city which caused extensive water logging. However, notably, the poor in Dhaka city are mostly vulnerable to flood hazards (Rashid 2000).

\subsection{POLITICAL INSTABILITY}

Cities are the sources of political turmoil and clash. Basically the capital city Dhaka is pioneer of all political movements and riots while government and their opposition execute governing apparatus and all political activities. The city's and overall country's development tremendously hindered by political instability which include dispute about free and fair elections; political meeting almost every day in the center part or commercially busiest part of the city; and intension of controlling the roads of the capital through terrorizing. Partisan politics and lack of neutrality of the leaders toward the common people also cause unequal development in the city. Political nepotism and corruption are also big factors behind poor governance and the failure in planning implementation. Political intervention also causes failure of law enforcement, which gets the terrorist unpunished. That is why; crime and violence have become almost a part of the city life. The administration turned utterly ineffective in fighting and curbing crimes (Islam2002). Therefore, the major challenges to developing cities like Dhaka are economic, social and ecological sustainability.

\subsection{ACCESS TO WATER}

The right to safe water is recognized as a foundation of all other human rights. Bangladesh has made significant progress regarding universal access to improved water sources, with more than 97 per cent of the population having access in 2013. But access to safe drinking water is still low at 34.6 per cent (UNICEF, 2021). The condition is worse in hilly terrains, urban slums, islands, coastal regions and wetlands, where there is still no reliable access to improved water sources. More than 2 million people in Bangladesh lack access to an improved water source and 48 million lack improved sanitation. In Bangladesh and around the world, millions are navigating the COVID-19 pandemic with the added challenge of living without access to safe water. Now more than ever access to safe water is critical to the health of families in Bangladesh. In, Dhaka, water and 
sanitation services are provided by Dhaka Water Supply and Sewerage Authority (DWASA), Department of Public Health and Engineering (DPHE) and Local Government and Engineering Department (LGED). There are some nongovernment organizations are working for water and sanitation besides government. Nonetheless, the services are still unsatisfactory, particularly in Dhaka city due to the fact of insecure access to safe water and sanitation in affordable cost (Islam, etal.2003).

At present, DWASA operates four water treatment plants and 404 deep tubewells, 38 high rise water reservoirs with $2,250 \mathrm{~km}$ water lines to supply 1,500 million liters of water per day. Before the inauguration of Sayedabad water treatment plant, $97 \%$ of the water supply was depended on deep tubewells and the rest were from the surface water. After commissioning this plant nearly $15 \%$ of supplied water are collected from surface water sources (Mesbah-us-Saleheen2003). According to the estimate by DWASA, it is possible only to supply 140-145 crore liters of water every day to Dhaka while the daily necessity of water is 160 crore liters. Similarly, a study reports DWASA is capable of supplying only 184 million liters of water ( $71 \%$ of the demand) per day for the population of about 10 million, while the demand of the consumers is 256 million liters per day.

Therefore, a only a very small part of city population are receiving adequate supply of piped water, and the rest of the people are experiencing inadequate supply, while the situation in slum dwellers and low income groups is unpleasant. To transform the city to a sustainable city access to safe water and sound sanitation need to be ensured.

\subsection{SOCIAL SECURITY AND PROTECTION}

Currently, Bangladesh has 114 disparate social protection programmes, primarily centered on food distribution and cash transfers. These programmes need to be better coordinated and integrated under a coherent institutional framework to ensure inclusive coverage of vulnerable populations to reduce social economic risks, food shortages and related hardships. According to the World Bank, there are 40 million Bangladeshis living in extreme poverty (surviving on less than $\$ 1.90$ per day). A further $30 \%$ of the populations are 'vulnerable,' defined as people with incomes slightly above the $\$ 1.90$ per day poverty threshold. These poor and vulnerable groups constitute 70 million individuals. Prior to the COVID-19 pandemic, it was estimated that 13 million working-age men and women were unemployed; a figure that has significantly increased during the current crisis.

Although the government are implementing different social safety net programmes, but because of some challenges, namely, inadequate coverage, wrong selection of beneficiaries, and disparity in regional distribution peoples are not getting proper support. 74.86 percent of the Dhaka city people do not feel safe. There are lots of fear and insecurities in daily life. This is very essential to ensure social security and protection to the city dwellers.

\subsection{CHALLENGES IN POPULATION SECTOR}

Dhaka is one of the fastest growing mega-cities in the world. Dhaka's 2021 population is now estimated at 21,741,090. In 1950, the population of Dhaka was 335,760 . Dhaka has grown by 735,230 since 2015, which represents a $3.50 \%$ annual change. These population estimates and projections come from the latest revision of the UN World Urbanization Prospects. These estimates represent the urban agglomeration of Dhaka, which typically includes Dhaka's population in addition to adjacent suburban areas. Nearly $36 \%$ of the urban population lives in Dhaka. For a better livelihood, more and more people are moving to urban areas like Dhaka. It's huge challenge. With proper planning, good governance and good management the population problems of Dhaka need to be solved to reach sustainable development goals.

Graph-6: Population growth trend in Dhaka city. 


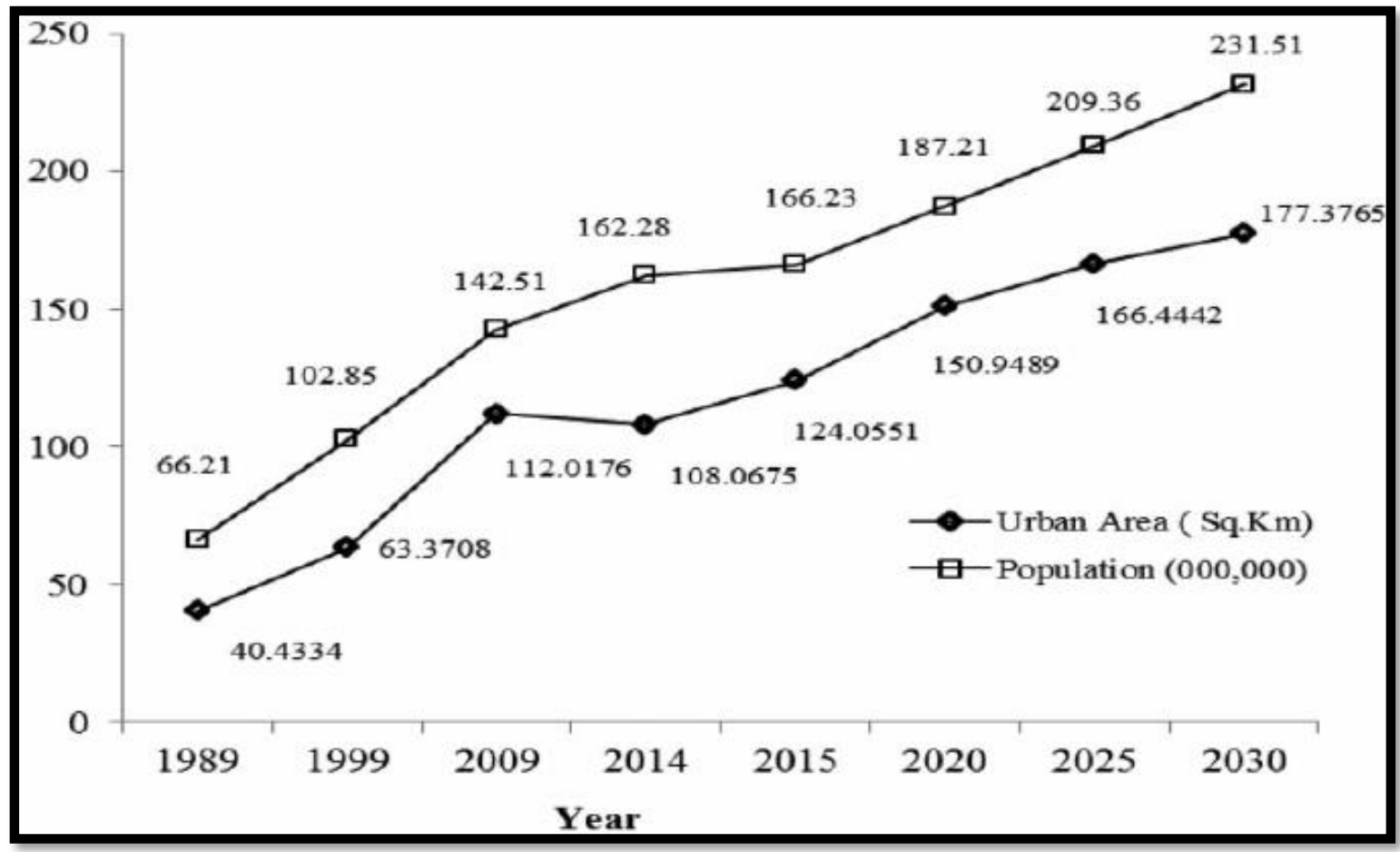

\subsection{OTHER CHALLENGES}

Besides the challenges have been expressed above, Bangladesh as well the Dhaka city has some other challenges in the way to achieve sustainable development. These challenges includes: poverty alleviation, microfinance for urban poor, reducing inequality and unemployment, human resource development, women empowerment, policy reform, decentralization, education, health, law and justice, human rights, rapid urbanization, corruption etc.

\subsection{RECOMMENDATIONS}

1. To overcome the existing obstacles and challenges confronted by the Dhaka city, substantial investments in the SDG pertinent projects are needed.

2. Increased investments are need on the areas of focus like basic infrastructures of the economy including roads, rail and ports; water and sanitation; food security and social safety; power and energy developments; climate change mitigation and adaptation; public health; and public services.

3. The most important prerequisite toward executing SDGs and transforming Dhaka to a sustainable city is to reduce inequality and increase the living standard of general city people.

4. Efficient new policies and projects should be initiated in clean energy (goal 7), work environment (goal 8), resource utility and mobilization, production and consumptions (goals 10, 12), sustainable cities (goal 11), good governance everywhere (goal 16.

5. Development will not be sustainable until a proper system of resources distribution and a healthy rate of economic growth are ensured.

6. Sustainable development requires efficient urbanization with standard modern facilities.

7. This is also very important to build strong democratic institutions and establish law and order in a proper way for effective governance.

\subsection{CONCLUSION}

There are lots of challenges to transform Dhaka city to a sustainable city. Major challenges in Dhaka city area were housing and infrastructure, industrialization, lack of land, water supply and waste management. Government of Bangladesh should address these problems properly and need to take proper plan to overcome these challenges. Government need to step to aware the people and compliance with the law. It is tough to face all of the challenges. But the government should prioritize the challenges and need to resolve these. We should be strategic and stay focused to overcome these challenges. If proper governments plan and efficient action takes place, and all parts of the plan works properly, Dhaka will be a sustainable city in someday. 


\subsection{REFERENCES}

[1] Mannan SM, Karim MM. Current State of the Mobility of the Urban Dwellers in Greater Dhaka. Paper for Presentation in 94th Annual Conference and Exhibition of Air and Waste Management Association, June 24-28, 2001, Orlando, Florida, USA.

[2] Islam N. Slums of Urban Bangladesh: Mapping and Census, 2005. MEASUREE valuation.

[3] Hossain, S. (2008). Rapid urban growth and poverty in Dhaka City. Ban e-J Socio, 5(1), 1-24.

[4] Joarder, S. Sustainable Development and the Urban Environment in Developing Countries: The experience of Dhaka.

[5] Rana, M. M. P. 2011. Urbanization and sustainability: challenges and strategies for sustainable urban development in Bangladesh. Environment, Development and Sustainability, 13(1), $237-256$. https://doi.org/10.1007/s10668-010-9258-4

[6] Mathur, O. P. (1999). Governing cities: Facing up to the challenges of poverty and globalization. India: The Challenge of Urban Governance, National Institute of Public Finance and Policy, New Delhi.

[7] Mesbah-us-Saleheen (2003). Water for the urban poor. Water and Sanitation for Cities. Dhaka: BIP and CUS.

[8] World Bank. Bangladesh 2020: A long-run perspective study. Dhaka: University Press Limited, 2003.

[9] Nazem, N. I. (2001). The concepts of urbanization and development. In N. Islam (Ed.), Urbanization, urban planning and development and urban governance: a reader for students. Dhaka, Bangladesh: Center for Urban Studies.

[10] Rana, M. M. P. (2009). Sustainable city in the global North and South: goal or principle. Management of Environmental Quality: An International Journal, 20(5), 506-521. https://doi.org/10.1108/14777830910981195

[11] Rasheed, K. B. S. (2003). Urban growth and water security challenges. Water and sanitation for cities. BIP and CUS, Dhaka.

[12] Rashid, S. F. (2000). The urban poor in Dhaka city: Their struggles and coping strategies during the floods of 1998. Disasters, 24(3), 240-253. https://doi.org/10.1111/1467-7717.00145

[13] Islam, N. (2001b). Good urban governance: an issue reemphasized (Editorial Notes). CUS Bulletin on Urbanization and Development, No. 41. Dhaka, Bangladesh: Center for Urban Studies.

[14] Islam, N. (2002). The Bangladesh urban environment (Editorial Notes). CUS Bulletin on Urbanization and Development, No.43.Dhaka, Bangladesh: Center for Urban Studies.

[15] Bhuiyan, S. H. (2010). A crisis in governance: Urban solid waste management in Bangladesh. Habitat International, 34(1), 125-33. https://doi.org/10.1016/j.habitatint.2009.08.002

[16] Murtaza, M. G. (2004). Urban disasters in Bangladesh: Some suggestions and concern. CUS Bulletin on Urbanization and Development, No. 46. Dhaka, Bangladesh: Center for Urban Studies.

[17] Rabinovitch, J. (1992). Curitiba: Towards sustainable urban development. Environment and Urbanization, 4(2), 62-73. https://doi.org/10.1177/095624789200400206

[18] Kaarin T. (2012). Challenges and way forward in the urban sector. Sustainable Development in the $21^{\text {st }}$ century (SD21). Report for the UN Department of Economic and Social Affairs. New York: UNDESA. 